\title{
EL CASO DE LAS COMUNIDADES CAUTIVAS DEL CHACO CHUQUISAQUEÑO: UNA MIRADA DESDE LOS ORGANISMOS INTERNACIONALES
}

\section{THE CASE OF THE CAPTIVE COMMUNITIES IN CHUQUISACA'S CHACO: A VIEW FROM THE INTERNATIONAL ORGANIZATIONS}

\author{
Ian Sergio Miranda Sánchez \\ Universidad Privada de Santa Cruz de la Sierra. Bolivia/Bolivia \\ ian.miranda@,outlook.com
}

Recibido/Received: 11/08/2014

Modificado/Modified: 21/08/2014

Aceptado/Accepted: 30/09/2014

\section{RESUMEN}

Este artículo examina la intervención de Organismos Internacionales en el Chaco chuquisaqueño. Debido a la existencia de comunidades cautivas en las haciendas chaqueñas, surgieron denuncias ante las instancias internacionales, quienes evidenciaron relaciones de servidumbre, trabajo forzoso y ausencia del Estado en la defensa y garantía de los derechos individuales y colectivos del pueblo Guaraní.

\section{PALABRAS CLAVE}

Derechos humanos, pueblos indígenas, reconstitución territorial, políticas estatales.

\section{SUMARIO}

1. Introducción. 2. Informes de organismos internacionales. 3. Consideraciones finales. Bibliografía.

\begin{abstract}
This article examines the involvement of International Organizations in Chuquisaca's Chaco. Due the existence of captive communities in Chaco's ranches, complaints arose to international instances that evidenced relationships of servitude, forced labor and the absence of the State in the defense and guarantee of individual and collective rights of the Guarani People.
\end{abstract}

\section{KEYWORDS}

Human rights, indigenous people, territorial reconstitution, state policy.

\section{CONTENTS}

1. Introduction: 2. Reports of international organizations. 3. Final considerations. References. 


\section{INTRODUCCIÓN}

\subsection{Comunidades cautivas y sistema de hacienda en el Chaco chuquisaqueño}

Sesenta y seis años después de la Independencia boliviana (1825), el pueblo guaraní fue perdiendo su libertad, a pesar de haber resistido la invasión de la colonia española. El 28 de enero de 1892, con intervención del ejército republicano, la relación servidumbral entre hacendados y guaraníes pudo consolidarse a partir de la batalla de Kuruyuki -en el Chaco chuquisaqueño. La paulatina adjudicación y posesión de tierras, desde inicios del siglo XIX, derivó la sucesión de conflictos servidumbrales y de trabajo forzoso. Albó (1989: 19), analizando la problemática guaraní, esquematizó la presencia patronal en tres hitos: conquista de territorio mediante el ganado; concesión estatal de territorio, como recompensa por la represión de indígenas tras la derrota de Kuruyuki; finalmente, mediante el asentamiento y/o compra de tierras, consideradas baldías y fiscales, desconociendo la presencia de comunidades guaraníes.

La débil presencia del Estado en regiones rurales fue justificada por Remberto Capriles y Gastón Ardúz, encargados de elaborar el Proyecto de Código de Trabajo de 1942. Manifestaron, en el preámbulo del Proyecto, la insuficiente experiencia de Bolivia en la legislación de políticas agrarias que sean eficaces en regiones alejadas de los centros urbanos; consideraron: "Aparte de la diversidad de regímenes de trabajo agrícola en Bolivia, el conocimiento incompleto que de ellos se tiene y la absoluta imposibilidad de desplazar hasta el campo los servicios de inspección de trabajo, constituirían, hoy por hoy, otros tantos obstáculos insuperables en esta materia."(Cabanellas, citando a Capriles y Gastón, 1987:67). De esta manera, la exclusión de los trabajadores rurales de la legislación agraria repercutiría al pueblo guaraní, quienes se encontrarían indefensos y marginados por el Estado, dando a lugar el despojo de tierras y al sometimiento de indígenas a un sistema de trabajo servil en aras del patronazgo. Esta situación entablaría la perennidad del problema laboral en el Chaco chuquisaqueño.

La Ley de Reforma Agraria de 1953 (LRA) no permitía que el latifundio sea un medio de captación de tierras, lo conceptuaba como: propiedades semi-feudales, de gran extensión, escasa producción donde "depende fundamentalmente de la plusvalía que rinden los campesinos en su condición de siervos o colonos y de la cual se apropia el terrateniente en forma de renta trabajo" (Art. 12, LRA). Según Healy (1987:40), la región del Chaco chuquisaqueño no alcanzó a implementar la Reforma Agraria en su totalidad, por a la presencia sistemática de hacendados en instituciones gubernamentales, resguardando las grandes extensiones en su haber. Él denominó a este proceso una contrarreforma a la normativa agraria, por el uso hegemónico del poder por parte de los latifundistas, quienes desconocieron las normas y políticas agrarias, considerando que contravenían sus intereses. Si bien la LRA permitía la dotación de tierras con preferencia a indígenas y campesinos, sometidos a regímenes semi-feudales, los hacendados del Chaco eludieron la normativa. Por consiguiente, desde el año 1996, se platearon demandas para consolidar Tierras Comunitarias de Origen (TCO), las cuales buscaron amparar los derechos de los pueblos indígenas mediante la reconstitución territorial, pensando que solucionaría el conflicto patróntrabajador. Para Almaraz, al permitir el proceso de reconstitución territorial, debían implementarse políticas estatales que empoderen la consolidación territorial de comunidades y/o pueblos indígenas para que establezcan su propiedad en sus tierras ancestrales. (Ver Ministerio de Justicia et al, 2006; y Rosso, 2010).

Por los hechos señalados, consideramos que pudo instaurarse la hacienda como institución, dado que son relaciones patronales, desfavorables para los indígenas, se han 
instaurado desde finales del siglo XIX, dando a lugar la consolidación de territorio de hacendados $\mathrm{y}$, ante la ausencia de Estado, las prácticas de trabajo forzoso y servidumbre por endeudamiento formaron parte del habitus laboral en la región chaqueña. Esta situación motivó la intervención de Organismos Internacionales.

\subsection{Tratados Internacionales: formas análogas de esclavitud}

La Convención sobre la Esclavitud de 1926, en su primer artículo, define la esclavitud como el "estado o condición de un individuo sobre el cual se ejercitan los atributos del derecho de propiedad sobre algunos". Los Estados americanos acordaron en la Convención Americana sobre Derechos Humanos que "nadie puede ser sometido a esclavitud o servidumbre, y tanto éstas como la trata de esclavos y la trata de mujeres están prohibidas en todas sus formas" (Art. 6.1). Ergo, ante la definición de la Convención de 1926, se derivaron conceptos de condiciones análogas a la esclavitud, como la servidumbre y trabajo forzoso. En este contexto la Convención Suplementaria sobre Abolición de la Esclavitud define la servidumbre, en el Art. 1(a) y (b), lo siguiente:

a. La servidumbre por deudas, o sea, el estado o la condición que resulta del hecho de que un deudor se haya comprometido a prestar sus servicios personales, (...) como garantía de una deuda, si los servicios prestados, equitativamente valorados, no se aplican al pago de la deuda, o si no se limita su duración ni se define la naturaleza de dichos servicios;

b. La servidumbre de la gleba, o sea, la condición de la persona que está obligada por la ley, por la costumbre o por un acuerdo a vivir y a trabajar sobre una tierra que pertenece a otra persona y a prestar a ésta, mediante remuneración o gratuitamente, determinados servicios, sin libertad para cambiar su condición.

Por otra parte, el Convenio No 29 de la Organización Internacional del Trabajo (OIT) en el Art. 2 (1), define al trabajo forzoso como "(...) todo trabajo o servicio exigido a un individuo bajo la amenaza de una pena cualquiera y para el cual dicho individuo no se ofrece voluntariamente". Esta pena puede tratarse de la privación de cualquier derecho o ventaja (O’Donell, 1989:107); verbigracia: sometimiento a trabajo forzoso por endeudamiento laboral.

Bajo estos tres conceptos, entendemos que el pueblo guaraní, según los instrumentos internacionales, fue sometido a condiciones de servidumbre y trabajo forzoso; en este sentido, las relaciones de esclavitud y semi-esclavitud no constituyeron parte del sistema laboral en el Chaco. Las deplorables condiciones de las familias empatronadas en la región del Chaco, en marco de los Tratados Internacionales, pudieron ser evidenciadas en los informes emitidos por Organismos Internacionales, invitados por el Estado Boliviano.

\section{INFORMES DE ORGANISMOS INTERNACIONALES}

\subsection{Informe de la Organización Internacional del Trabajo}

La intervención de Organismos Internacionales, preocupados por la situación de servidumbre en la región del Chaco boliviano, inició sus actividades el año 2004, a través de la investigación "Enganche y Servidumbre por Deudas en Bolivia" de la OIT. El estudio manifestó su preocupación por la situación del pueblo guaraní "donde trabajadores indígenas guaraníes laboran bajo un sistema servil y donde algunas comunidades se encuentran cautivas en el interior de haciendas agrícolas y/o ganaderas.”(Beyoda et al., 2005:47). Pudo constatarse que el sistema de servidumbre por deudas resultó del anticipo de pago en bienes 
(especie) y/o dinero, originando un endeudamiento, con la finalidad de retener a los trabajadores. Los estudios de campo para el informe se realizaron en haciendas de los departamentos que conforman el territorio guaraní en Bolivia: Santa Cruz (provincia Cordillera), Chuquisaca (provincia Hernando Siles y Luis Clavo) y Tarija (provincia Gran Chaco y O'Connor).

\subsubsection{Situación de servidumbre laboral}

De acuerdo a la OIT, la debilidad institucional posibilitó que las prácticas de servidumbre y trabajo forzoso dilaten el conflicto patronal. Desde la década del setenta, los hacendados cumplieron funciones como autoridades públicas en las instancias locales, departamentales y nacionales (Beyoda et al., 2005: 47), permitiendo la imposición de sus demandas e intereses respecto a la posesión de tierras y toma de decisiones políticas. Una muestra de las relaciones de poder, influencia política y concentración de tierras es la siguiente:

“a) El señor Federico Reynaga es un propietario que, (...), cuenta con 4 haciendas que son: Itarumau (con 1.800 has. aproximadamente), Itani/Ingre, que colinda con la comunidad de Tentayapi con una superficie de 2.670 has., Inti, con 650 ha., e Iguembito con aproximadamente 3.000 ha.

b) Federico Reynaga ha sido corregidor entre los años 1999 a 2004.

c) En la gestión municipal anterior fue electo concejal.

d) Actualmente tiene el cargo de consejero departamental." (Ministerio de Justicia et al., 2006:55)

Otra de las preocupaciones del Estado y la OIT se enmarcó en las condiciones de trabajo. El informe pudo constatar que el pago de jornales oscilaba entre Bs.- 10 y 15 (1,2 y 1,5 Euros de acuerdo a las cotizaciones del año 2004), resaltando la inequidad entre hombres y mujeres. Ante la reducida remuneración se añade la figura del endeudamiento patronal, donde el hacendado es dueño de las mercaderías que vende a sus trabajadores, con un precio superior al del mercado, produciendo una relación de servidumbre laboral. De acuerdo a la OIT, el endeudamiento llega a someter al trabajador, obligándolo a quedarse a disposición del empleador hasta poder pagar la deuda, sin poder desplazarse a otras regiones: "Dicho régimen de relaciones laborales, posibilita mantener las cuantiosas deudas que someten a los trabajadores guaraníes que les impide migrar libremente a otras zonas de Bolivia donde los salarios son más altos.”(Beyoda et al., 2005:53).

\subsubsection{Recomendaciones de la OIT}

El gobierno boliviano había manifestado su voluntad para elaborar una estrategia que elimine el trabajo forzoso ante la OIT (2005:45), por este motivo Bolivia y Perú se comprometieron, el año 2004, a erradicar el trabajo forzoso en ambos países, impulsando y proponiendo una agenda legislativa que erradique las formas de trabajo forzoso, enfatizando sus actividades, en el caso boliviano, con el pueblo guaraní, en aplicación del Convenio $\mathrm{N}^{\mathrm{o}}$ 29 de la OIT.

De igual modo la OIT mencionó la necesidad de incrementar los recursos humanos y económicos en las Regionales de Trabajo, donde se evidencien situaciones de trabajo forzoso. Para esto, observaron la necesidad de un trabajo interinstitucional entre Estado y Organizaciones No Gubernamentales (ONG), pudiendo elaborar proyectos y programas que sensibilicen a la sociedad acerca problemática laboral, difundiendo los Tratados Internacionales que rechacen formas análogas a esclavitud. Otra de las recomendaciones consistió en la adopción de un Plan de Acción Nacional de erradicación y lucha contra el trabajo forzoso en todas sus formas y la promulgación de normativas accesorias al Plan que 
aseguren una relación laboral estable y digna por parte de los hacendados hacia sus trabajadores -acciones que fueron paulatinamente progresivas. En cuanto al empoderamiento de tierras por el pueblo guaraní, se recomendó acelerar el proceso de saneamiento según la Ley $\mathrm{N}^{\mathrm{o}} 1715$. De esta manera procedería la reversión de propiedades de hacendados que incumplan normativas laborales en contra de los guaraníes.

\subsection{Informe del Relator Especial de 2007}

Bolivia, en el año 2007, invitó al Relator Especial sobre la situación de los derechos humanos y las libertades fundamentales de los Pueblos Indígenas de las Naciones Unidas. La visita del Relator se realizó desde el 25 de noviembre al 7 de diciembre de 2007. El objetivo de la visita consistió en analizar el contexto indígena en Bolivia y elaborar propuestas que eviten las violaciones a los derechos humanos y libertades fundamentales.

A pesar de la desigualdad en la tenencia de tierras, donde el $90 \%$ de los agricultores, principalmente indígenas, sólo poseen el 10\% de las tierras productivas a comparación del 90\% que la disponen los grandes propietarios (ONU, 2008:13). Stavenhagen dio méritos a la implementación de la Ley No 3545 de Reconducción Comunitaria de la Reforma Agraria que reformularía la Ley $\mathrm{N}^{0}$ 1715, permitiendo incorporar la reversión de tierras por incumplimiento de la función económico-social, para regular las desigualdades asimétricas en la posesión de tierras. A pesar de la reconfiguración de la Ley $\mathrm{N}^{\circ} 1715$, su implementación no pretendía ser acatada en el Chaco. Por este motivo, en mayo de 2005, el ex presidente Carlos Mesa promulgó el Decreto Supremo No 28159, definiendo los conceptos de "familias cautivas y/o empatronadas"; estableciendo el registro de familias y comunidades cautivas e incorporando la figura de la servidumbre laboral en la Ley General del Trabajo. El gobierno de Mesa permitió reconocer la existencia de las relaciones servidumbrales en el Estado, además de iniciar la consolidación de territorio del pueblo guaraní. La implementación de la Ley permitiría la dotación de tierras a los pueblos indígenas, debido a que las tierras expropiadas serían tierras fiscales las cuales: (...) serán dotadas de oficio o a solicitud de parte interesada, exclusivamente a favor de pueblos indígenas y/o originarios que como resultado del proceso de saneamiento de la propiedad agraria ni con la distribución de tierras fiscales hayan sido dotados con tierra suficiente en cantidad, calidad y ubicación geográfica para asegurar su subsistencia física y reproducción étnica. (Art. 34. II; Ley $\mathrm{N}^{\circ}$ 3545).

Asimismo, el Relator pudo constatar la existencia de trabajo forzoso y relaciones de servidumbre en el Chaco, como un sistema laboral gratuito, personal y obligatorio, coaccionado o establecido fraudulentamente, incluyendo las servidumbres laborales por deudas. Sin embargo, reconoció el trabajo desarrollado por el Estado para erradicar condiciones laborales sometidas a trabajo forzoso y/o servidumbre a través del Plan Interministerial Transitorio (PIT) 2007-2008. Este Plan, elaborado por sugerencias de otros Organismos Internacionales, tuvo la intención de impulsar la reconstitución territorial de la nación guaraní, garantizando sus derechos individuales y colectivos y promover el desarrollo productivo.

\subsection{Informe del Foro Permanente para Cuestiones Indígenas de las Naciones Unidas}

Bolivia solicitó, en el séptimo periodo del Foro Permanente para las Cuestiones Indígenas de las Naciones Unidas, la intervención de una Misión que pueda verificar las denuncias de prácticas de trabajo forzoso y servidumbre en comunidades guaraníes. La Misión contó con la participación de distintos Organismos Internacionales, entre ellos la OIT, ONU y la 
Organización para la Alimentación y la Agricultura (FAO), los trabajos de campo se realizaron entre abril y mayo de 2009.

La Misión constató la existencia de trabajo forzoso de hombres y mujeres, frecuentemente sometidos a servidumbre y endeudamiento por sus empleadores y la dificultad al acceso a tierras. El patronazgo en el Chaco configuraría un obstáculo para el Estado boliviano en la implementación de políticas de reversión de propiedades que contravengan la función económico-social a favor de las comunidades guaraníes. Además, de la problemática tierraterritorio, las condiciones laborales presentan desigualdades y asimetrías, donde en algunos casos los hacendados no efectuaban el pago de jornales a las mujeres, en uno de los testimonios recogidos por la Misión (ONU, 2010b:25) señalaban que hombres y mujeres trabajaban de 6 de la mañana a seis de la noche, sin descansos los fines de semana, habiendo casos donde las mujeres no cobraban por los servicios solicitados por los patrones o percibiendo salarios inferiores a comparación de los hombres. Además, de los pagos desiguales, la Misión pudo evidenciar la existencia de maltratos físicos y violencia de hacendados contra sus trabajadores.

Bolivia, en el Código Niño Niña y Adolescente, ha fijado la edad mínima para trabajar a los catorce años, no obstante la situación en el Chaco es adversa a la normativa, la Misión pudo constatar la existencia de trabajo infantil no remunerado. Asimismo, los menores del Chaco se encuentran en situaciones de riesgo, por la existencia de abuso sexual y se encuentran desfavorecidos por la escasa educación que brinda el Estado.

Por otra parte, según la Misión, la libertad de asociación de guaraníes a la "Asamblea del Pueblo Guaraní" (APG) es restringida por los hacendados, quienes la consideran como una traición por parte de los trabajadores. Además, la frágil institucionalidad no permite la imparcialidad en los sistemas administrativo y judicial, los cuales benefician a los hacendados. Cabe señalar que la débil presencia del Estado no permitió el desarrollo pleno del PIT, el eslabón de conflictos se enlaza con las autoridades políticas (quienes obstaculizaron el desarrollo del PIT), las exiguas actuaciones del Tribunal Agroambiental y la reducida presencia del gobierno nacional en el Chaco.

\subsubsection{Recomendaciones del Foro Permanente para Cuestiones Indígenas de la ONU}

El año 2009, el Foro Permanente de Naciones Unidas emitió una serie de recomendaciones concerniente a la situación del pueblo guaraní en la región del Chaco boliviano. Este documento cimienta algunas bases para erradicar las condiciones de servidumbre y trabajo forzoso en el Chaco chuquisaqueño. Ver Tabla 1: Recomendaciones de la Misión.

\subsection{Informe de la Comisión Interamericana de Derechos Humanos, 2007}

La Comisión Interamericana de Derechos Humanos (CIDH) realizó una visita in loco, a invitación del gobierno de Bolivia, para observar la situación de los derechos humanos en el país -del 12 al 17 de noviembre de 2006. Debemos comprender que al momento de la visita tres sucesos convulsionaron el panorama político y social del Estado boliviano: la Asamblea Constituyente (agosto), el conflicto minero de Huanuni (octubre) y el Cabildo del Millón (diciembre). Para la CIDH (2007:VII) "el contexto político y social de los últimos años que, caracterizado por la fragilidad institucional y la persistencia de los conflictos sociales, ha dificultado el diseño e implementación de medidas tendientes a superar dichos problemas, principalmente la falta de acceso a la justicia y la exclusión social.”. A pesar de la situación social convulsa, la Comisión consideró que la promulgación de la Ley $\mathrm{N}^{\circ} 3545$ representaría un salto cualitativo para los pueblos indígenas, al permitir la dotación de tierras a indígenas 
por causales de expropiación o reversión a propiedades que incumplan la función económico-social.

Tabla 1. Recomendaciones de la Misión

\begin{tabular}{|c|c|}
\hline Ejes & Recomendaciones \\
\hline $\begin{array}{l}\text { Consentimiento } \\
\text { previo, libre e } \\
\text { informado }\end{array}$ & $\begin{array}{l}\text { - Adoptar planes de acción para acabar con las prácticas de trabajo forzoso y } \\
\text { discriminación de los pueblos indígenas, aplicando las recomendaciones del } \\
\text { Foro previo consentimiento e información a los pueblos indígenas. } \\
\text { - Ajustar estatutos autonómicos al régimen constitucional, teniendo en cuenta } \\
\text { la erradicación de toda forma análoga de esclavitud, con el consentimiento } \\
\text { previo de los pueblos indígenas. }\end{array}$ \\
\hline & $\begin{array}{l}\text { - Fortalecer la presencia de instituciones gubernamentales en zonas afectadas } \\
\text { por las prácticas de trabajo forzoso (presencia de: Defensor del Pueblo; } \\
\text { Ministerios: Público; Trabajo, Empleo y Previsión Social; Educación; Salud } \\
\text { Deportes; Culturas; Viceministerios: Descolonización; Interculturalidad). } \\
\text { - Asignar y asegurar recursos económicos de los funcionarios estatales. } \\
\text { - Resguardar la seguridad física de los trabajadores en las Regionales de } \\
\text { Trabajo y miembros de ONG. } \\
\text { - Capacitar a miembros del órgano judicial y policías en materia de Derechos } \\
\text { Humanos. } \\
\text {-Aplicar Tratados y Convenios en materia de Derechos Humanos. } \\
\text { - Sancionar a personas que amenacen la libre asociación de indígenas a la } \\
\text { APG. }\end{array}$ \\
\hline $\begin{array}{l}\text { Financiación y } \\
\text { Reforma } \\
\text { Agraria }\end{array}$ & $\begin{array}{l}\text { - Transferir recursos económicos a organizaciones e instituciones indígenas } \\
\text { en marco del PIT. } \\
\text { - Realizar planes y proyectos entre el Ministerio de Trabajo, Empleo y } \\
\text { Previsión Social y el Instituto Nacional de Reforma Agraria (INRA), en } \\
\text { coordinación con el pueblo guaraní. } \\
\text { - Dar celeridad a los procesos de saneamiento, concesión y redistribución de } \\
\text { la tierra a los pueblos indígenas. } \\
\text { - Garantizar el acceso al agua, alimentación y educación. }\end{array}$ \\
\hline $\begin{array}{l}\text { PIT, desarrollo } \\
\text { y cooperación } \\
\text { internacional }\end{array}$ & $\begin{array}{l}\text { - Aplicar políticas de desarrollo, por el gobierno departamental y nacional, en } \\
\text { las comunidades indígenas hasta que consoliden sus autonomías. } \\
\text { - Garantizar la salud, educación y seguridad social, de acuerdo al marco } \\
\text { competencial de la Constitución Política del Estado de } 2009 \text {. } \\
\text { - Contar con apoyo técnico y financiero de la ONU, para garantizar la } \\
\text { seguridad alimentaria en la región. } \\
\text { - Asegurar la participación de organizaciones indígenas en la evaluación de } \\
\text { los logros propuestos por el PIT y otros Planes concernientes al pueblo } \\
\text { guaraní. } \\
\text { - Celebra de acuerdos y programas transfronterizos (Bolivia-Paraguay) para } \\
\text { la erradicación del trabajo forzoso, y recepción de denuncias de guaraníes } \\
\text { (bolivianos) en soberanía paraguaya; estos acuerdos bilaterales deberán } \\
\text { celebrarse conforme al consentimiento de los pueblos indígenas del Chaco. }\end{array}$ \\
\hline $\begin{array}{l}\text { Participación, } \\
\text { diálogo social y } \\
\text { fin de la } \\
\text { discriminación }\end{array}$ & $\begin{array}{l}\text { - Adoptar medidas que luchen contra la discriminación. } \\
\text { - Reforma del acceso al Registro Civil, sin que se efectúe desplazamientos a } \\
\text { núcleos urbanos. } \\
\text { - Iniciar el proceso de conciliaciones laborales entre patrones y } \\
\text { organizaciones indígenas o sindicales, para mejorar la situación del pueblo } \\
\text { guaraní. }\end{array}$ \\
\hline
\end{tabular}


No obstante, la CIDH expresó su preocupación por las condiciones de servidumbre y trabajo forzoso de las familias guaraníes. Estimaron que 600 familias viven sometidas a sistemas análogos de esclavitud, consecuente a la falta plena de reconstitución territorial y ausencia institucional del Estado. La Misión tomó en cuenta la situación de servidumbre y trabajo forzoso con los pueblos indígenas, mencionando que el peligro de esta situación "se ve exacerbada por la falta de respuesta estatal tanto en las instancias administrativas como judiciales, así como por la ausencia de políticas integrales dirigidas a solucionar la problemática con toda la complejidad que ella comporta.” (CIDH, 2007:XI-XII). Los agentes de la CIDH (2007:78) confirmaron la existencia de prestaciones de trabajo remuneradas deficientemente; por ende, ante la falta de necesidades básicas de subsistencia, los trabajadores llegan a endeudarse con sus patrones "por la provisión de víveres, ropa y otros productos, que puede llegar a ser vitalicia e incluso heredarse."; mientras que los hacendados niegan tales condiciones, considerando estas acciones como históricamente superadas, siendo estas afirmaciones contradictorias con la realidad. Otra de las preocupaciones es la tenencia de tierras de los hacendados, que se subdivide y hereda entre familias de hacendados, contrastando con la situación de las familias guaraníes.

A diferencia de informes emitidos por otros Organismos, la CIDH es crítica respecto a la operatividad de funcionarios públicos en el Chaco boliviano, por el incumplimiento o trasgresión de las normas relativas a derechos humanos y en otras circunstancias la situación es adversa, no hay la presencia de instituciones estatales, lo que dificulta mantener una prelación en la defensa de los derechos laborales y humanos de los trabajadores indígenas.

\subsubsection{Recomendaciones de la Comisión Interamericana de Derechos Humanos, 2007}

La CIDH, en su informe, emitió recomendaciones muy reducidas en cuanto a las condiciones de trabajo del pueblo guaraní, debido a los diferentes ejes que consideraron en la Misión. Recomendaron priorizar los planes y proyectos para eliminar las relaciones de servidumbre y trabajo forzoso. Asimismo, consideraron necesario fortalecer el proceso de titulación de tierras a pueblos indígenas y elaborar un diagnóstico que identifique a todas las familias sometidas a servidumbre -en particular a los actores involucrados en el conflictoconsiderando las deficiencias de las distintas instancias gubernamentales.

\subsection{Informe de la Comisión Interamericana de Derechos Humanos, 2009}

La CIDH publicó, el 25 de abril de 2008, un comunicado de prensa, manifestando la deplorable situación de las comunidades cautivas en Bolivia. El comunicado exhortaba al Estado boliviano a tomar medidas que erradiquen las condiciones servidumbrales en el Chaco, además de cumplir con el proceso de titulación de tierras a los pueblos indígenas. De la misma forma, se instó al Gobierno boliviano a adoptar medidas necesarias para que se resguarde el respeto a los derechos humanos, consecuente con los hechos de violencia en los procesos saneamiento de tierras (Ver CIDH, 2008).

Debido a las denuncias del pueblo guaraní, el 11 de marzo de 2008, durante el 131 periodo ordinario de sesiones de la $\mathrm{CIDH}$, se instauró una audiencia sobre el estado de las comunidades cautivas del pueblo guaraní en el Chaco boliviano. Los peticionarios (miembros de organizaciones indígenas y ONG) presentaron información sobre las violaciones a los derechos humanos de las familias cautivas, dirigentes indígenas y sus representantes legales. A raíz de la audiencia, se pudo efectuar un compromiso, signado por los peticionarios y los representantes del gobierno de Bolivia, puesto que "Este fenómeno, conocido como "comunidades cautivas" representan indudablemente formas contemporáneas de esclavitud que deben ser erradicadas de manera inmediata.”(CIDH, 2009:7). En el Acta de 
Compromiso, el gobierno Boliviano asumió la responsabilidad de resguardar los derechos humanos de las familias guaraníes y recibir la visita del Relator sobre Derechos de Pueblos Indígenas, para constatar los hechos que restrinjan la reconstitución territorial y la liberación de las familias cautivas.

La visita in loco constató la existencia de violencia física por parte de los hacendados, asumiendo una postura paternalista frente sus trabajadores. Además, se observó el pago ínfimo de jornales, división de labores por estereotipos de género -dando a lugar una inequidad de pagos y distinto trato laboral- y trabajo infantil (Ver Ministerio de Justicia et al., 2006: 49). Consecuente a la servidumbre laboral, pudo evidenciarse el escaso acceso a educación y la pérdida paulatina de usos y costumbres de las familias guaraníes, como también la restricción a la libre asociación, derecho coartado por los hacendados, quienes buscaron mecanismos para impedir la asociación de sus trabajadores a la APG, castigando a quienes se afiliara por despido o expulsión, imposibilitándoles la oportunidad de trabajar en otras haciendas.

El Estado boliviano, según la Misión, debería cumplir con el acceso a la propiedad al pueblo guaraní, cumpliendo con el Art. 14.1 de la Convención $\mathrm{N}^{\mathrm{o}} 169$ de la OIT donde "deberá reconocerse a los pueblos interesados el derecho de propiedad y de posesión sobre las tierras que tradicionalmente ocupan (...)"; el acceso a tierras [propiedad] debería ser otorgado colectivamente. Referente al acceso a la justicia, la Misión consideró que se debe adoptar procedimientos justos y equitativos con los guaraníes, tomando en cuenta las normas y procedimientos propios de la nación indígena.

\subsubsection{Recomendaciones de la Comisión Interamericana de Derechos Humanos, 2009}

Bolivia, al ser un Estado soberano, está obligada a cumplir la normativa internacional concerniente a Derechos Humanos. El cumplimiento de tales disposiciones es inexcusable, ante su incumplimiento, cualquier Estado es pasible de sanciones punibles por la Comunidad Internacional. El gobierno boliviano, por su inobservancia con el pueblo guaraní, no puede invocar a disposiciones internas, como justificación por el incumplimiento de un tratado (Convención de Viena, Art. 27), en este caso la erradicación de las formas análogas a la esclavitud.

La CIDH consideró importante, no sólo erradicar las relaciones servidumbrales, sino reconstituir el territorio guaraní, asumiendo medidas integrales, por parte de los tres niveles de gobierno, para permitir un acceso a la educación, salud y vivienda en los territorios guaraníes. A su vez, el Estado es responsable de asegurar las medidas para la reconstitución del territorio guaraní, como el saneamiento, expropiación y reversión de tierras, la cual debe resguardar la subsistencia de las familias vivientes, garantizando el acceso a los recursos naturales que puedan disponer. La Misión sugirió que se investigue y sancione a las personas que continúen aplicando sistemas servidumbrales y de trabajo forzoso, para esto, se deberá fortalecer la estructura judicial, articulando la jurisdicción penal con la agraria, dando celeridad en las etapas investigativas y procesales.

Una de las recomendaciones de la CIDH consistió en la adopción de políticas y leyes eficaces para la reivindicación territorial guaraní. Para esto, consideraron necesario que el Estado fortalezca su institucionalidad, asegurando la presencia de autoridades laborales en la región del Chaco y otorgando el acceso gratuito de asistencia jurídica. 


\section{CONSIDERACIONES FINALES}

Obligación axiológica y cumplimiento de las recomendaciones de Organismos Internacionales por el Estado boliviano.

La situación del pueblo guaraní fue estudiada con detenimiento por las distintas Misiones, llegando a tener conclusiones en común y emitiendo recomendaciones similares, verbigracia: reconstitución territorial, presencia institucional del Estado, desarrollo de las disposiciones del PIT, elaboración de una agenda legislativa, entre otros avances. Aunque, se presenta un retroceso sustancial: la promulgación de la Ley $\mathrm{N}^{\mathrm{o}} 429$ del 31 de octubre de 2013, la cual amplía por 4 años los procesos de saneamiento, dificultando la reconstitución territorial demandada tiempo atrás por pueblos indígenas e impidiendo el ejercicio de sus derechos culturales y de propiedad en sus territorios (Ver Stavenhagen (ed.) et al., 2010:214-215).

Las intervenciones de los distintos Organismos, desde 2004, develó la deplorable situación de los guaraníes, evidenciándose una violación persistente de los derechos humanos del pueblo guaraní. Consideramos que fue una violación sistemática porque se establecía con la presencia de hacendados en instituciones públicas, en los gobiernos locales y departamentales y fue persistente por la perennidad del problema, a más de un siglo desde la batalla de Kuruyuki. Siendo que la soberanía comprende la totalidad del territorio de un Estado, la garantía y defensa de los derechos fundamentales por parte de los gobiernos fue deplorable debido a su ausencia institucional. Considerando los informes presentados por los Organismos Internacionales, hay que aclarar que no son vinculantes ni obligatorios ante la Comunidad Internacional, por no ser instrumentos de carácter ius cogens, no obstante, sentaron pautas para la elaboración de nuevas políticas que prevengan relaciones servidumbrales y de trabajo forzoso en el Chaco, como en el resto del país.

Constatada la realidad, respecto a la desprotección de los Derechos Humanos del pueblo guaraní, es obligación del Estado garantizar y proteger sus derechos fundamentales, para que el reconocimiento formal de los mismos sea efectivo, aplicando los Tratados Internacionales ratificados por el Estado boliviano. En consideración a las recomendaciones de los informes, es una obligación axiológica y moral del Estado gestionar nuevas políticas que prevengan situaciones similares como las acaecidas en el Chaco, aplicando principios y preceptos reconocidos ante la Comunidad Internacional contenidos en las Convenciones Internacionales relativas a los derechos humanos de los pueblos indígenas, como la Convención $\mathrm{N}^{\circ} 169$ de la OIT (Art. 20, inc. c) donde se considera que "los trabajadores pertenecientes a estos pueblos no estén sujetos a sistemas de contratación coercitivos, incluidas todas las formas de servidumbre por deudas" o la Declaración de la ONU sobre los derechos de los Pueblos Indígenas, que aduce que los indígenas "tienen derecho a no ser sometidas a condiciones discriminatorias de trabajo" (Art. 17). Futuros gobiernos deben asegurar las garantías necesarias para evitar la existencia de comunidades cautivas, sometidas a servidumbre por deudas y trabajos forzosos.

\section{BIBLIOGRAFÍA}

ALBÓ, X. (1989). Los Guaraní-Chiriguano 3: la comunidad de hoy. La Paz: Centro de Investigación y Promoción del Campesinado.

BEYODA, G. y BEYODA, E. (2005). Enganche y Servidumbre por Deudas en Bolivia. Ginebra: Organización Internacional del Trabajo. 
CABANELLAS, G. (1987). Tratado de derecho laboral: doctrina y legislación iberoamericana. Tomo II, Vol. IV, Buenos Aires: Editorial Heliasta S.R.L.

CAPÍTULO BOLIVIANO DE DERECHOS HUMANOS, DEMOCRACIA Y DESARROLLO (2005). Estado de situación de los Derechos Económicos, Sociales y Culturales en Bolivia al año 2005. Bolivia: Capítulo Boliviano de Derechos Humanos, Democracia y Desarrollo.

CENTRO DE ESTUDIOS JURÍDICOS E INVESTIGACIÓN SOCIAL, et al. (2013). Diagnóstico básico para las capacidades de formación sociopolítica del pueblo guaraní. Santa Cruz de la Sierra: CEJIS, CAP, CCCH.

CHARTERS, A. y STAVENHAGEN, R. (eds.) (2010). El desafío de la Declaración. Historia y futuro de la Declaración de la ONU sobre Pueblos Indígenas. Copenhagen: International Work Group for Indigenous Affairs.

COMISIÓN INTERAMERICANA DE DERECHOS HUMANOS (CIDH) (2007). Acceso a la justicia e inclusión social: el camino hacia el fortalecimiento de la democracia en Bolivia OEA/Ser.L/V/II. Doc. 34. Washington, D.C.: Organización de Estados Americanos.

- (2008). Comunicado de prensa, $N^{o}$ 17/08. Washington D.C.: Organización de Estados Americanos.

- (2009). Comunidades Cautivas: situación del pueblo guaraní y formas contemporáneas de esclavitud en el Chaco de Bolivia. OEA/Ser.L/V/II. Doc. 34. Washington, D.C.: Organización de Estados Americanos.

HEALY, K. (1987). Caciques y patrones: una experiencia de desarrollo rural en el sur de Bolivia. Cochabamba: Centro de Estudios de la Realidad Económica.

MINISTERIO DE JUSTICIA, et al. (2006). Quiero ser libre, sin dueño. La Paz: Plural Editores.

O’DONNELL, D. (1989). Protección Internacional de los Derechos Humanos. Lima: Comisión Andina de Juristas.

ORGANIZACIÓN DE ESTADOS AMERICANOS (OEA) (1969). Convención Americana sobre Derechos Humanos. Washington D.C.: Organización de Estados Americanos.

- (2008). Acta de compromiso: Audiencia sobre Comunidades Cautivas 2/4/2008-SM-5001725. Washington D.C.: Organización de Estados Americanos.

ORGANIZACIÓN DE LAS NACIONES UNIDAS (ONU) (1948). Declaración Universal de Derechos Humanos. París: Organización de las Naciones Unidas.

- (1969). Convención de Viena sobre el derecho de los tratados. U.N. Doc A/CONF.39/27. Nueva York: Organización de las Naciones Unidas.

(2007). Declaración sobre derechos de los Pueblos Indígenas. Nueva York: Organización de las Naciones Unidas.

- (2008). A/HRC/9/11/Add. 2: Informe del Relator Especial sobre la situación de los derechos humanos y las libertades fundamentales de los indígenas, Sr. Rodolfo Stavenhagen. Nueva York: Organización de las Naciones Unidas.

- (2010a). Información recibida de los gobiernos: Estado plurinacional de Bolivia. Nueva York: Organización de las Naciones Unidas.

- (2010b). Foro permanente de las Naciones Unidas para las cuestiones Indígenas: Misión Bolivia, Informe y Recomendaciones. La Paz: Alto Comisionado de las Naciones Unidas para los Derechos Humanos, PDG Impresiones.

ORGANIZACIÓN INTERNACIONAL DEL TRABAJO (OIT) (1989). Convenio 169 de la OIT Sobre Pueblos Indígenas y Tribales en Países Independientes. Ginebra: Organización Internacional del Trabajo.

- (2005). Una alianza global contra el trabajo forzoso: informe global con arreglo al seguimiento de la declaración de la OIT relativa a los principios y derechos fundamentales del trabajo. Ginebra: Organización Internacional del Trabajo.

PIFARRÉ, F. (1989). Los Guaraní-Chiriguano 2: historia de un pueblo. La Paz: Centro de Investigación y Promoción del Campesinado.

ROSSO, A. (2010). "Entrevista a Alejandro Almaraz Ossio: Semiesclavitud de familias guaraníes del Chaco boliviano". En Artículo Primero, Revista de debate Social y Jurídico: Derechos humanos de los pueblos indígenas y nueva constitución. Año 13, 20: 61-65. 
VALDEZ, M. y ROJAS, C. (2003). "A medio camino: Reforma Agraria en el Chaco". En Artículo Primero, Revista de debate Social y Jurídico: Reforma Agraria, 50 años: TCO y Tierras Campesinas. Año 7, 14: 349-364.

\section{Breve currículo:}

\section{Ian Sergio Miranda Sánchez}

Asistente jurídico en asuntos de Pueblos Indígenas en la Oficina Regional Santa Cruz del Centro de Estudios Jurídicos e Investigación Social (CEJS). 